01.1;01.4;05.2;05.3;06.1

\title{
Изменение температуры Кюри в пористом материале
}

\author{
(C) А.В. Шишулин ${ }^{1}$, В.Б. Федосеев ${ }^{1}$, А.В. Шишулина ${ }^{2,3}$ \\ ${ }^{1}$ Институт металлоорганической химии им. Г.А. Разуваева РАН, Нижний Новгород, Россия \\ 2 Дзержинский политехнический институт (филиал) Нижегородского государственного технического университета \\ им. Р.Е. Алексеева, Дзержинск, Россия \\ ${ }^{3}$ Нижегородский государственный университет им. Н.И. Лобачевского, Нижний Новгород, Россия \\ E-mail: chichouline_alex@live.ru
}

Поступило в Редакцию 10 марта 2020 г.

В окончательной редакции 7 апреля 2020 г.

Принято к публикации 9 апреля 2020г.

\begin{abstract}
Рассмотрена зависимость температур магнитного превращения пористых ферромагнитных материалов от геометрических характеристик (объема и формы) распределенных в материале нанопор. Геометрические особенности нанопор задавались величинами их эффективного радиуса и коэффициента формы, характеризующего степень отклонения формы поры от сферической. Приведенные оценки свидетельствуют о возможности получения макроскопических образцов пористых материалов с пониженной температурой Кюри, величина которой дополнительно снижается при „усложнении“ формы нанопор. Результаты получены в рамках когезионной модели на примере чистых пористых никеля и кобальта.
\end{abstract}

Ключевые слова: наноструктурирование, пористые материалы, ферромагнетизм, магнитные превращения, температура Кюри.

DOI: 10.21883/PJTF.2020.14.49657.18281

Наноструктурированные ферромагнитные материалы являются в настоящее время объектом значительного интереса исследователей [1]. Внимание к таким материалам обусловлено как широким спектром технологических приложений ферромагнитных наноструктур [2], так и массой явлений, представляющих фундаментальный интерес (см., например, $[1,3,4])$. Одним из параметров, характеризующих устойчивость свойств ферромагнитных материалов, является температура Кюри - температура разрушения магнитной упорядоченности ферромагнетика и его перехода в парамагнитное состояние (фазового перехода второго рода). Известно, что при нанометровых характерных размерах частиц ферромагнитного материала температура Кюри (как и ряд других параметров $[4,5])$ является функцией их размера [5-8] и формы $[7,8]$, что связано с ростом доли низкоскоординированных атомов приповерхностного слоя, обладающего отличными от вещества в „объеме“ магнитными характеристиками (магнитными моментами, значениями обменных интегралов и констант магнитной анизотропии [5]), при уменьшении размера и усложнении формы наночастицы. Учет данных закономерностей возможен в рамках ряда существенно различных подходов [1,5-8].

Следует отметить, что формирование нанопорошкового материала или нанокомпозитов, содержащих распределенные в матрице или на подложке ферромагнитные наночастицы [7], не является единственным путем получения материалов с высокой долей атомов приповерхностного слоя. Высокие значения удельных поверхностей достижимы и в материалах с распределенными ансамблями нанопор (до $500 \mathrm{~m}^{3} / \mathrm{g}$ [9] или даже до нескольких тысяч $\left.\mathrm{m}^{3} / \mathrm{g}[10]\right)$, при этом сами объекты могут иметь макроскопические размеры. Формирование такого рода структур возможно, например, на начальных стадиях процессов электроимпульсного или лазерного спекания нанопорошков [11].

Объектом моделирования является пористый материал с заданной объемной долей пор $\alpha$. Поры могут иметь достаточно сложную геометрическую конфигурацию $[12,13]$, для описания которой воспользуемся двумя параметрами: эффективным диаметром поры $d_{e f f}$, численно равным диаметру сферы, объем которой равен объему рассматриваемой поры, и коэффициентом формы $k$, равным отношению площади поверхности рассматриваемой поры $A$ к площади поверхности сферы равного объема $A_{0}: k=A / A_{0}$ (более детально подобный подход описан ранее в [12-15] и не является единственным, см., например, [12,15-17]). Число пор в $1 \mathrm{~g}$ материала $N_{p o r}$ может быть найдено как $N_{p o r}=6 \alpha \cdot 1 \mathrm{~g} /\left(\pi \rho d_{e f f}^{3}\right)$, где $\rho$ - плотность материала, множитель $1 \mathrm{~g} \mathrm{вве-}$ ден для согласования размерностей; удельная поверхность $A_{s p}$ равна $A_{s p}=N_{p o r} \pi k d_{e f f}^{2}=6 \alpha k \cdot 1 \mathrm{~g} /\left(\rho d_{e f f}\right)$. Для оценки влияния числа и геометрических характеристик нанопор на температуру Кюри воспользуемся простой закономерностью: связью температуры Кюри материала с его энергией когезии [18], полученной в работах [6-8]: $T_{c}^{\text {por }} / T_{c}^{\text {bulk }}=E_{c o h}^{\text {por }} / E_{c o h}^{\text {bulk }}$ (экспериментальная проверка данного соотношения проведена авторами [6], схожий подход использован для описания данного и ряда других типов фазовых превращений авторами $[19,20]$, также продемонстрировано соответствие экспериментальным результатам). Здесь $E_{c o h}^{p o r}$ и $E_{c o h}^{b u l k}$ - энергии когезии пористого и „сплошного“ материалов соответственно, $T_{c}^{p o r}$ и $T_{c}^{b u l k}$ - температуры 

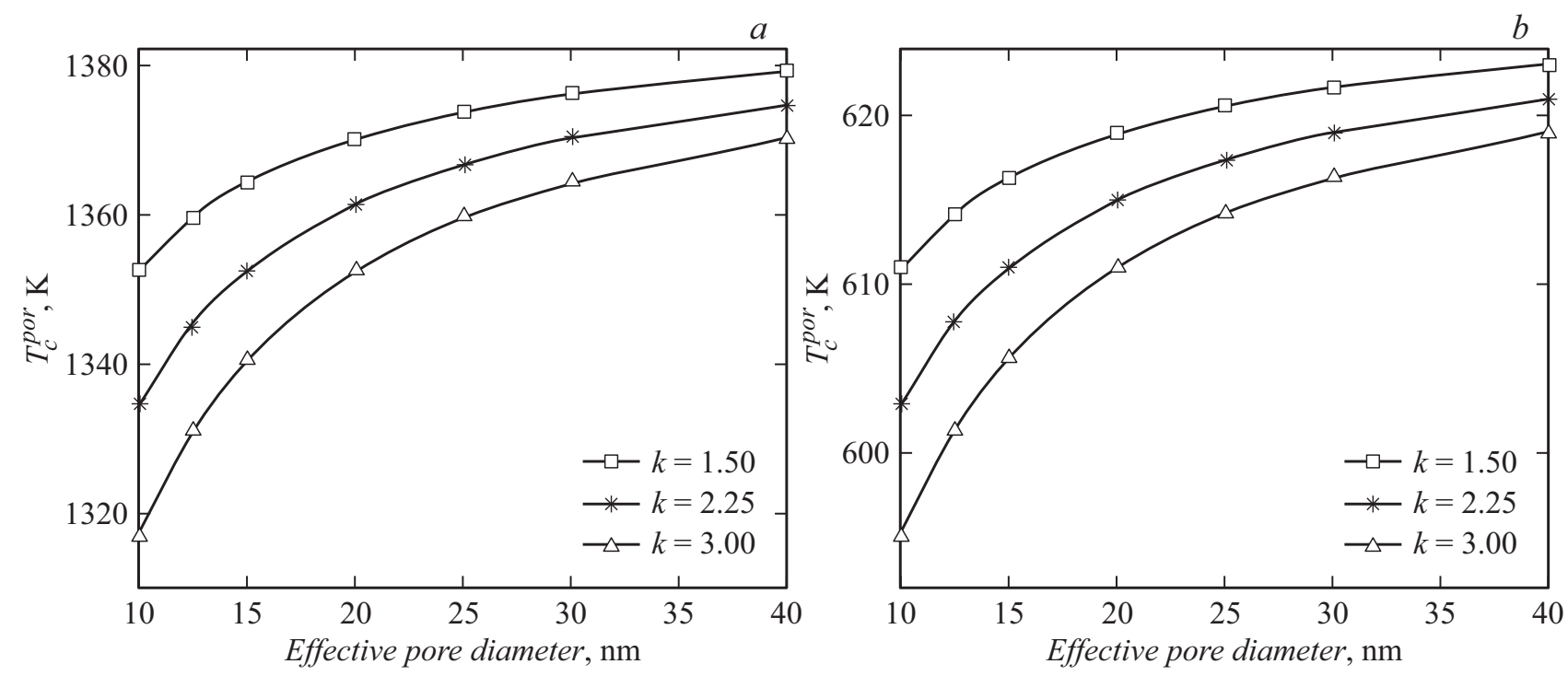

Зависимость температуры Кюри пористого материала $T_{c}^{\text {por }}$ от эффективного диаметра и коэффициента формы поры $k$ для кобальта $(a)$ и никеля $(b)$. Температуры Кюри данных металлов для объемных беспористых объектов макроскопического размера составляют 1388 и $627 \mathrm{~K}$ соответственно.

Кюри пористого материала и материала в отсутствие пор. В $1 \mathrm{~g}$ пористого материала содержится $N$ атомов: $N=6 \omega \cdot 1 \mathrm{~g} /\left(\pi d_{a t}^{3} \rho\right)$, где $d_{a t}-$ диаметр атома, $\omega-$ плотность упаковки атомов в кристаллической структуpe. Из них на стенках пор располагаются $N_{s}$ атомов: $N_{s}=\eta A_{s p} / \pi d_{a t}^{2}=6 \alpha \eta k \cdot 1 \mathrm{~g} /\left(\pi \rho d_{a t}^{2} d_{e f f}\right)$, где $\eta-$ плотность упаковки атомов на поверхности материала. Таким образом,

$$
N_{s}=\left(\frac{6 \cdot 1 \mathrm{~g}}{\pi \rho}\right)^{1 / 3} \frac{\alpha \eta k}{\omega^{2 / 3} d_{e f f}} N^{2 / 3}
$$

Оценки для энергии когезии пористого материала получим на основе соотношений, предложенных авторами [18]:

$$
\begin{gathered}
E_{\text {coh }}^{\text {bulk }}=\frac{1}{2} \beta N \varepsilon_{b}, \\
E_{c o h}^{\text {por }}=\frac{1}{2} \beta \varepsilon_{b}\left(\frac{1}{4} N_{s}+\left(N-N_{s}\right)\right),
\end{gathered}
$$

где $\beta$ - первое координационное число, а $\varepsilon_{b}-$ энергия одной связи. Таким образом, из (1), (2) с учетом приведенного выше следует

$$
T_{c}^{\text {por }}=T_{c}^{\text {bulk }}\left(1-\frac{3}{4}\left(\frac{6 \cdot 1 \mathrm{~g}}{\pi \rho}\right)^{1 / 3} \frac{\alpha \eta k}{\omega^{2 / 3} d_{e f f}} N^{1 / 3}\right) .
$$

Выражение (3) позволяет получить оценки температуры Кюри материала как функции объемной доли и геометрических характеристик пор. На рисунке приведены зависимости температуры Кюри для пористых кобальта $(a)$ и никеля $(b)$ от величин $d_{e f f}$ и $k$. В настоящих расчетах мы ограничились рассмотрением материалов с невысокими в сравнении с объектами исследований $[9,10]$ удельными поверхностями пор, не превышающими $200 \mathrm{~m}^{3} / \mathrm{g}\left(\alpha=0.70\right.$; величины $\rho$ и $d_{a t}$ составляют
$8.900 \mathrm{~g} / \mathrm{cm}^{3}$ и $250 \mathrm{pm}$ для $\mathrm{Co}, 8.902 \mathrm{~g} / \mathrm{cm}^{3}$ и $248 \mathrm{pm}$ для $\mathrm{Ni}$ соответственно). Кобальт имеет две стабильные полиморфные модификации: $\alpha$-Со с гексагональной структурой и $\beta$-Со со структурой ГЦК, устойчивой в рассматриваемой области температур (температура полиморфного превращения $\alpha \rightarrow \beta$ составляет $\sim 427^{\circ} \mathrm{C}$ ), в свою очередь никель обладает ГЦК-структурой во всей области температур до температуры плавления. Плотность упаковки атомов в объеме для кристаллов с ГЦК-структурой составляет $\omega \approx 0.74$; для плотности упаковки атомов на поверхности для ГЦК-структур в [21] приведена оценка $\eta \approx 0.91$, использованная также и в [19].

Как показано на рисунке, присутствие пор, увеличение коэффициента формы поры $k$ и уменьшение эффективного диаметра поры $d_{e f f}$ (рост величины удельной поверхности) приводят к заметному снижению температуры Кюри материала. Отметим, что присутствие, например, жидкости, заполняющей поры, может привести к некоторой коррекции данных оценок (учет наполненности пор возможен в рамках подхода, изложенного в [7]). Предложенная зависимость (3), описывающая эффект понижения температуры Кюри в пористом материале, соответствует приближению распределенных в материале изолированных пор одинакового размера и формы. Дополнительного уточнения полученных оценок можно добиться путем использования при расчете величины удельной поверхности $A_{s p}$ функций распределения пор по размерам и форме (пример подобных распределений, полученных экспериментально, приведен в [22]), а также учета возможного слияния пор с образованием пор „червеобразной“ структуры, что приводит к некоторому понижению удельной поверхности за счет исчезновения перемычек. Данные уточнения могут привести к некото- 
рой коррекции величины температуры Кюри $T_{c}^{p o r}$ за счет изменения поверхности $A_{s}$, но не меняют полученных в работе закономерностей.

Следует также отметить, что широкий спектр технологических приложений пористых материалов включает в себя, например, матрицы нанореакторов с порами, заполняемыми реакционной смесью (см. ссылки в [12]). Для значительного числа приложений представляют интерес магнитокалорические эффекты в ферромагнитных структурах, например хорошо описанный в литературе нагрев ферромагнитных наночастиц-инвазивных агентов в переменных магнитных полях (вследствие гистерезисных потерь, потерь на переориентацию вектора намагниченности и т.д.), служащий терапии раковых опухолей [5], где предел роста температуры частицы задан определяющейся морфологией точкой Кюри. В таком случае пористых ферромагнитных материалов принципиальная возможность задания температуры Кюри путем использования объектов с соответствующей объемной долей и морфологией пор позволяет получать матрицы с заданным самоограничением повышения температуры. При этом рассмотренные ферромагнитные материалы отличаются высокой каталитической активностью в ряде широко используемых реакций [20], а в материалах с большей удельной поверхностью пор $[9,10]$ ожидаемо более существенное понижение температуры Кюри вплоть до подобного описанному в [5].

\section{Финансирование работы}

Работа выполнена в рамках государственного задания ИМХ РАН, а также при поддержке Российского фонда фундаментальных исследований (проект № 18-08-01356A).

\section{Конфликт интересов}

Авторы заявляют, что у них нет конфликта интересов.

\section{Список литературы}

[1] Ferrando R. // Front. Nanosci. 2016. V. 10. P. 245-266.

[2] Nanomagnetism: fundamentals and applications / Ed. C. Binns. Elsevier, 2014. V. 6. 328 p.

[3] Здоровейщев А.В., Вихрова О.В., Демина П.Б., Дорохин М.В., Кудрин А.В., Темирязев А.Г., Темирязева М.П. // ФTT. 2019. Т. 61. В. 9. C. 1628-1633.

[4] Столяр С.В., Комогориев С.В., Чеканова Л.А., Ярославцев Р.Н., Баюков О.А., Великанов Д.А., Волочаев М.Н., Черемискина Е.В., Bairmani M.Sh., Ерошенко П.Е., Исхаков Р.С. // Письма в ЖТФ. 2019. Т. 45. В. 17. С. 28-30.

[5] Никифоров В.Н., Игнатенко А.Н., Ирхин В.Ю. // ЖЭТФ. 2017. T. 151. B. 2. C. $356-363$.

[6] He X., Zhong W., Au C.-T., Du Y. // Nanoscale Res. Lett. 2013. V. 8. P. 446.

[7] Cao L.-F., Xie D., Guo M.-X., Park H.S., Fïjita T. // Trans. Nonferrous Met. Soc. China. 2007. V. 17. P. 1451-1455.
[8] Delavari H., Hosseini H.M., Simchi A. // Chem. Phys. 2011. V. 383. P. 1-5.

[9] Гаев Д.С., Рехвиашвили С.Ш. // ФТП. 2012. Т. 46. В. 2. C. $145-149$.

[10] Chae H.K., Siberio-Pŕez D.Y., Kim J., Go Y., Eddaoudi M., Matzger A.J., O'Keeffe M., Yaghi O.M. // Nature. 2004. V. 427. P. 523-527.

[11] Ерофеева И.В., Дорохин М.В., Здоровейщев А.В., Кузнецов Ю.М., Попов А.А., Ланцев Е.А., Боряков А.В., Котомина В.Е. // ФТП. 2018. Т. 52. В. 12. С. 1455-1459.

[12] Shishulin A.V., Fedoseev V.B. // J. Mol. Liq. 2019. V. 278. P. 363-367.

[13] Шишулин А.В., Федосеев В.Б. // Письма в ЖТФ. 2019. T. 45. B. 14. C. $10-12$

[14] Федосеев В.Б., Шишулин А.В. // ФТТ. 2018. Т. 60. В. 7. C. $1382-1388$.

[15] Шишулин А.В., Федосеев В.Б., Шишулина А.В. // ЖТФ. 2019. T. 89. B. 4. C. $556-561$.

[16] Шишулин А.В., Федосеев В.Б., Шишулина А.В. // ЖТФ. 2019. T. 89. B. 9. C. $1420-1426$.

[17] Магомедов М.Н. // Письма в ЖТФ. 2016. Т. 42. В. 14. C. 94-102.

[18] Aqra F., Ayyad A. // Appl. Surf. Sci. 2014. V. 324. P. 308-313.

[19] Guisbiers G. // Nanoscale Res. Lett. 2010. V. 5. P. 1132-1136.

[20] Guisbiers G., Abudukelimu G. // J. Nanopart. Res. 2013. V. 15. P. 1431.

[21] Attarian Shandiz M. // J. Phys.: Condens. Matter. 2008. V. 20. 325237.

[22] Chuvil'deev V.N., Nokhrin A.V., Kopylov V.I., Boldin M.S., Vostokov M.M., Gryaznov M.Y., Tabachkova N.Y., Tryaev P. // J. Mater. Sci. 2019. V. 54. P. 14926-14949. 